\title{
Genç Meme Kanseri İle Çok Genç Meme Kanseri Moleküler Altgruplarının Prognostik Faktörlerle ilișkisi
}

\author{
Relationship of Young Breast Cancer and Very Young Breast Cancer \\ Molecular Subgroups with Prognostic Factors
}

\author{
Sertaç Ata GÜLER (D), Saffet ÇINAR (D), Alican GÜREȘiN (D), Turgay ȘiMȘEK (D), \\ Nuh Zafer CANTÜRK (D), Nihat Zafer UTKAN \\ Kocaeli Üniversitesi Tıp Fakültesi, Genel Cerrahi Anabilim Dalı, Kocaeli, Türkiye \\ ORCID ID: Sertaç Ata Güler 0000-0003-1616-9436, Saffet Çınar 0000-0003-3637-1922, Alican Güreșin 0000-0002-7724-2724, \\ Turgay Șimșek 0000-0002-5733-6301, Nuh Zafer Cantürk 0000-0002-0042-9742, Nihat Zafer Utkan 0000-0002-2133-3336
}

Bu makaleye yapılacak atıf: Güler SA ve ark. Genç Meme Kanseri ille Çok Genç Meme Kanseri Moleküler Altgruplarının Prognostik Faktörlerle ilișkisi. Med J West Black Sea. 2021;5(2):162-165.

Calıșma 11-13 Ekim 2018'de Breastanbul Konferansı-3. Meme Kanseri Konferansı, İstanbul 'da poster bildiri olarak sunulmustur.

Sorumlu Yazar

Alican Güreșin

E-posta

alicanguresin@icloud.com

Geliș Tarihi

18.12.2020

Revizyon Tarihi

01.02.2021

Kabul Tarihi

03.02.2021
Öz

Amaç: Genç meme kanseri, 40 yaş altında meme kanseri tanısı almış hasta grubunun tanımıdır. Genç yaş meme kanseri grubunun prognozu çok kötüdür. Buna ek olarak, meme kanseri 35 yaşın altında tanısı konulduğunda çok genç meme kanseri grubu olarak adlandırılır ve prognoz genç meme kanseri grubundan çok daha kötüdür.

Gereç ve Yöntemler: Çalışmanın amacı genç meme kanseri hastalarının moleküler alt grupları ve prognostik faktörler değerlendirilerek çok genç meme kanseri grubu ile karşıllaştırılmasıdır. Çalışmada Kocaeli Üniversitesi Tıp Fakültesi Genel Cerrahi Anabilim Dalı Meme Cerrahisi Ünitesi'nde Ekim 2013Şubat 2018 tarihleri arasında meme kanseri tanısı alan 624 hasta değerlendirildi.

Bulgular: İki grup arasında demografik veriler, patolojik veriler, moleküler sınıflandırma ve hastalık sağkalım verileri açısından istatistiksel olarak anlamlı bir fark saptanmadı. Sağkalım analizinde çok genç meme kanseri grubu ile genç meme kanseri grubu arasında istatistiksel olarak anlamlı fark bulunmadı.

Sonuç: Genç meme kanseri grubunun hem hastalık özellikleri hem de sağkalım açısından daha kötü olduğu görüldü. Ancak özellikle moleküler alt gruplar ve prognoz açısından çok genç meme kanseri grubu ile genç meme kanseri grubu arasında fark bulunmadı ve ayrı bir grup olarak tedavi edilmesi gerekmediği sonucuna varıldı.

Anahtar Sözcükler: Meme kanseri, Genç meme kanseri, Çok genç meme kanseri, Moleküler altgruplar, Prognostik faktörler

\section{ABSTRACT}

Aim: Young breast cancer is a description of a patient group diagnosed with breast cancer, especially those under 40 years of age. The prognosis of younger age group is very poor.

Material and Methods: The aim of the study is to compare young breast cancer patients with the very young breast cancer group by evaluating molecular subgroups and prognostic factors.

Results: No statistically significant difference was found between the two groups in terms of demographic data, pathological data, molecular classification and disease survival data. In the survival analysis, there was no statistically significant difference between very young breast cancer group and young breast cancer group.

Conclusion: Young breast cancer is worse in terms of both disease characteristics and survival. But especially in terms of molecular subgrouping and in terms of prognosis very young breast cancer group may not need to be treated as a separate group other than the young breast cancer group.

Keywords: Breast cancer, Young breast cancer, Very young breast cancer, Molecular subtypes, Prognostic factors 


\section{GiRiş}

Meme kanseri özellikle gelişmiş ülkelerde, genç yaş kadınlarda kanser ilişkili ölümlerin başında gelmektedir (1). Genç meme kanseri genelde daha ender görülmekle birlikte daha fazla önem teşkil etmekte ve sonuçları daha kötü seyretmektedir. Bunun sebebi de elverişsiz klinikopatolojik özellikler, daha agresif tümör biyolojisi ve tanıda gecikmedir. Bu sebeplerle prognozu daha kötü, nüks riski daha fazladır $(2,3)$. Genç meme kanseri özellikle 40 yaş altında meme kanseri tanısı konulmuş hasta grubu için yapılmış tanımlamadır (4). Ayrıca çok genç meme kanseri grubu 35 yaş altında meme kanseri tanısı konulmuş hasta grubudur (5).

$\mathrm{Bu}$ çalışmada literatürde verilen bu bilgilere göre, genç meme kanseri hastalarının moleküler altgrupları ve prognostik faktörleri değerlendirilerek, çok genç meme kanseri grubu ile karşılaştırması yapılarak, çok genç meme kanseri hastalarının prognostik açıdan ayrı bir alt grup olarak değerlendirilebilirliğini ortaya koymaktır.

\section{GEREÇ ve YÖNTEMLER}

Çalışmamızda Kocaeli Üniversitesi Tıp Fakültesi Genel Cerrahi Kliniği'nde Ekim 2013 ile Şubat 2018 tarihleri arasında meme kanseri tanısı ile opere edilmiş 624 hasta değerlendirmeye alındı. Bu hastaların içinden 40 yaş altı kliniğimizde meme kanseri histopatolojik tanısı ile cerrahi yapılan hastalar çalışmaya alındı. Hastaların verileri retrospektif olarak, hastane kayıtlarından taranmış, eksik veriler hastalara ulaşılarak elde edildi. Hastaların demografik, patolojik, moleküler ve sağkalım ile ilgili verileri toplandı. Elde edilen bu veriler kendi içinde 35 yaş ve altı ile 36 ile 40 yaş arası grup olarak ikiye bölündü ve istatistiksel değerlendirme yapıldı.

Kocaeli Üniversitesi Tıp Fakültesi Girişimsel Olmayan Klinik Araştırmalar Etik Kurulu'nun 21.05.2020'de 2020/137 proje numarası ile projenin yürütülmesi uygun bulunmuştur. Bu çalışmada araştırma ve yayın etiğine uyuldu.

İstatistiksel değerlendirme, IBM SPSS 20.0 (IBM Corp., Armonk, NY, USA) paket programı ile yapıldı. Normal dağılıma uygunluk testi Kolmogorov-Smirnov Testi ile değerlendirildi. Normal dağılım göstermeyen nümerik değişkenler medyan (25.- 75. persentil), kategorik değişkenler ise frekans (yüzdelikler) olarak verildi. Gruplar arasındaki farklılık nümerik değişkenler için Mann Whitney U Testi ile belirlendi. Kategorik değişkenler arasındaki ilişkiler ise Fisher Exact Kikare, Yates Kikare ve Monte Carlo Kikare analizi ile değerlendirildi. İki yönlü hipotezlerin testi için $p<0.05$ istatistiksel önemlilik için yeterli kabul edildi.

\section{BULGULAR}

Çalışmanın sonucunda, verilen tarihler arasında ameliyat edilmiş olan 624 meme kanseri hastasının içinden 95 has- tanın 40 yaş ve altında olduğu tespit edildi. Bu grup içinde en düşük yaş 22'ydi. Yine bu 95 adet 40 ve altı yaş meme kanserinin 36 tanesi 35 yaş ve altı grubundayken (ortalama 31,64 yaş), 59 tanesi de 36 ile 40 yaş arasındaki gruptaydı (ortalama 37,73 yaş). Çok genç grup olarak değerlendirilen 35 yaş ve altı grubu ile 36 ile 40 yaş arası grup hastaların demografik ve patolojik verileri Tablo 1'de, moleküler sınıflandırmaya ait verileri Tablo 2'de, hastalık durumuna ait verileri Tablo 3'te verildi.

Çalışmamızdaki 35 yaş ve altı meme kanseri grubunun 1 (\%2,8)'i erkek, 35 (\%97,2)'i kadındı. 36 ile 40 yaş arası meme kanseri grubunun hepsi kadındı. Çalışmamızdaki 35 yaş ve altı meme kanseri grubunun 26 (\%72,2)'sı neoadjuvan kemoterapi tedavisi almamış, 10 (\%27,8)'u almıştır. 36 ile 40 yaş arası meme kanseri grubunda $41(\% 69,5)$ hasta neoadjuvan kemoterapi tedavisi almamış $18(\% 30,5)$ hasta almıştır. 35 yaş ve altı meme kanseri grubunda $20(\% 55,6)$

Tablo 1. Demografik ve patolojik veriler

\begin{tabular}{|c|c|c|c|}
\hline & \multicolumn{2}{|c|}{ Yaş Grupları } & \multirow{3}{*}{ p } \\
\hline & \multirow{2}{*}{$\begin{array}{c}35 \text { Yaş Altı } \\
\mathrm{n}(\%)\end{array}$} & \multirow{2}{*}{$\begin{array}{c}\text { 36-40 Yaş Arası } \\
\mathrm{n}(\%)\end{array}$} & \\
\hline & & & \\
\hline Cinsiyet & & & 0,37 \\
\hline Erkek & $1(2,8)$ & $0(0,0)$ & \\
\hline Kadın & $35(97,2)$ & $59(100,0)$ & \\
\hline Lateralite & & & 0,49 \\
\hline Sol & $19(52,8)$ & $27(45,8)$ & \\
\hline Sağ & $17(47,2)$ & $30(50,8)$ & \\
\hline Bilateral & $0(0,0)$ & $2(3,4)$ & \\
\hline Neoadjuvan tedavi & & & 0,95 \\
\hline Hayır & $26(72,2)$ & $41(69,5)$ & \\
\hline Evet & $10(27,8)$ & $18(30,5)$ & \\
\hline Meme cerrahisi şekli & & & 0,96 \\
\hline Mastektomi & $21(58,3)$ & $36(61,0)$ & \\
\hline Meme koruyucu cerrahi & $15(41,7)$ & $23(39,0)$ & \\
\hline Mastektomi şekli & & & 0,29 \\
\hline Subkutan & $0(0,0)$ & $4(6,8)$ & \\
\hline Basit & $36(100,0)$ & $56,5(93,2)$ & \\
\hline Aksillaya İşlem & & & 0,87 \\
\hline SLNB $^{*}$ & $12(33,3)$ & $17(28,8)$ & \\
\hline Direkt diseksiyon & $20(55,6)$ & $34(57,6)$ & \\
\hline SLNB pozitif diseksiyon & $4(11,1)$ & $8(13,6)$ & \\
\hline Aksilla durumu & & & 0,90 \\
\hline Negatif & $14(38,9)$ & $25(42,4)$ & \\
\hline Pozitif & $22(61,1)$ & $34(57,6)$ & \\
\hline Tümör boyutu & & & 0,80 \\
\hline $2 \mathrm{~cm} \mathrm{Altı}$ & $20(55,6)$ & $30(50,8)$ & \\
\hline $2-5 \mathrm{~cm}$ & $12(33,3)$ & $19(32,2)$ & \\
\hline 5 cm Üzeri & $4(11,1)$ & $10(16,9)$ & \\
\hline Histolojik tip & & & 0,76 \\
\hline İnvaziv Duktal Karsinom & $27(75)$ & $48(81,4)$ & \\
\hline İnvaziv Lobüler Karsinom & $2(5,6)$ & $3(5,1)$ & \\
\hline Mixed & $2(5,6)$ & $1(1,7)$ & \\
\hline Diğer Tipler & $5(13,9)$ & $7(11,9)$ & \\
\hline
\end{tabular}

$\mathrm{n}(\%),{ }^{*}$ : Sentinel lenf nodu biyopsisi 
hastanın tümör boyutu $<2 \mathrm{~cm}, 12(\% 33,3)$ hastanın $2-5 \mathrm{~cm}$ arası, $4(\% 11,1)$ hastanın $>5 \mathrm{~cm}$ 'dir. 36 ile 40 yaş arası meme kanseri grubunda $30(\% 50,8)$ hastanın tümör boyutu $<2 \mathrm{~cm}, 19(\% 32,2)$ hastanın 2-5 cm arası, $10(\% 16,9)$ hastanın $>5 \mathrm{~cm}$ 'dir. 35 yaş ve altı meme kanseri grubunda sırasıyla genel sağkalım (GS) ortalaması 22,5 ay, hastalıksız sağkalım (HS) ortalaması 21 ay'dır. 36 ile 40 yaş arası meme kanseri grubunda ise genel sağkalım ortalaması 15 ay, hastalıksız sağkalım ortalaması 14 ay'dır (Tablo 4).

\section{TARTIŞMA}

35 yaş ve altı yani çok genç yaş tanımı uluslararası literatürde kullanılan farklı eşik değerler dikkate alınarak kullanılmıştır. Aslında, bu tanım için kriterlerin heterojenliği vardır. Bazı yayınlarda $<30$ yaş, bazı yayınlarda $<35$ yaş ve bazı yayınlarda da $<40$ yaş ve hatta tüm premenopozal hastalara atıfta bulunulmaktadır (6).

Genç yaş meme kanseri, ileri yaş meme kanseri ile karşılaştırıldığında, genç yaş meme kanseri hastalarının özellikle daha ileri evre olmaları, hormon reseptör negatif olmaları, yüksek grad mevcudiyeti, HER2 pozitifliği, triple negatif moleküler altgrup olmaları ve yüksek oranda lenfovasküler invazyon yapmaları temel farkları olmaktadır. Meme kanserine ait sağkalım oranlarına bakıldığında genç yaş meme kanserinin ileri yaşa göre çok daha kötü olduğu görülmektedir $(7,8)$.

Yine bu genç yaş meme kanseri grubu içerisinde, çok genç yaş olarak tanımlanan 35 yaş altı hasta grubunda bu özellik-

Tablo 2: Moleküler sınıflandırmaya ait veriler

\begin{tabular}{|c|c|c|c|}
\hline & \multicolumn{2}{|c|}{ Yaş Grupları } & \multirow{3}{*}{$\mathbf{p}$} \\
\hline & 35 Yaş Altı & 36-40 Yaş arası & \\
\hline & $n(\%)$ & $n(\%)$ & \\
\hline$\overline{E R}$ & & & 0,99 \\
\hline Negatif & $11(30,6)$ & $18(30,5)$ & \\
\hline Pozitif & $25(69,4)$ & $41(69,5)$ & \\
\hline ER (median) & $60(0-95)$ & $80(0-95)$ & 0,63 \\
\hline $\mathrm{PR}$ & & & 0,58 \\
\hline Negatif & $15(41,7)$ & $20(33,9)$ & \\
\hline Pozitif & $21(58,3)$ & $39(66,1)$ & \\
\hline PR (median) & $20(0-80)$ & $30(0-80)$ & 0,69 \\
\hline HER2 & & & 0,21 \\
\hline Negatif & $19(52,8)$ & $40(67,8)$ & \\
\hline Pozitif & $17(47,2)$ & $19(32,2)$ & \\
\hline Ki67 & & & 0,54 \\
\hline Negatif $(<\% 14)$ & $7(19,4)$ & $16(27,1)$ & \\
\hline Pozitif ( $\geq \% 14)$ & $29(80,6)$ & $43(72,9)$ & \\
\hline Ki67 (median) & $20(15-48,75)$ & $20(10-40)$ & 0,48 \\
\hline Moleküler Altgruplar & & & 0,10 \\
\hline Luminal A & $10(27,8)$ & $13(22,0)$ & \\
\hline Luminal B & $16(44,4)$ & $28(47,5)$ & \\
\hline HER2 & $8(22,2)$ & $6(10,2)$ & \\
\hline Triple (-) & $2(5,6)$ & $12(20,3)$ & \\
\hline
\end{tabular}

n (\%), ER: Östrojen reseptörü, PR: Progesteron reseptörü ler daha kötü prognozu işaret etmektedir. 35 yaş altı meme kanseri grubunda hastalık çok daha agresif ve sağkalım daha düşüktür. Amerikan Ulusal Kanser Veri Tabanı' nın bir incelemesi, 35 yaşından küçük hastaların tanıda daha ilerlemiş hastalığa sahip olduklarını ve daha yaşlı premenopozal hastalara göre daha kötü 5 yıllık sağkalıma sahip olduklarını ortaya koymaktadır (9).

Meme kanseri tedavisinde meme koruyucu cerrahi ve radyoterapi sonrası lokal nüks oranı genç hastalarda daha fazla görülmektedir $(10,11)$. Çalışmamızda ise her iki grup arasında nüks oranları açııından anlamlı bir ilişki olmadığı görüldü $(p=1,00)$.

Collins ve ark.nın 40 yaş altı genç meme kanseri hastalarında yaptıkları çalışmalarında Luminal B oranının Luminal A'ya göre daha yüksek olduğu görülmektedir (\%35'e \%33) (12). Bizim verilerimizdede literatüre paralel olarak Luminal B oranının fazla olduğu görülmüştür. Ancak moleküler altgruplar açısından genç ve çok genç meme kanserleri arasında istatistiksel bir ilişki olmadığı saptandı $(p=0,10)$.

Tablo 3: Hastalık durumuna ait veriler

\begin{tabular}{|c|c|c|c|}
\hline & \multicolumn{2}{|c|}{ Yaş Grupları } & \multirow{3}{*}{ p } \\
\hline & \multirow{2}{*}{$\begin{array}{c}35 \text { Yaş Altı } \\
\mathrm{n}(\%)\end{array}$} & \multirow{2}{*}{$\begin{array}{c}\text { 36-40 Yaş Arası } \\
\mathrm{n}(\%) \\
\end{array}$} & \\
\hline & & & \\
\hline Sağkalım & & & 0,99 \\
\hline Ölü & $2(5,6)$ & $4(6,8)$ & \\
\hline Sağ & $34(94,4)$ & $55(93,2)$ & \\
\hline Nüks yeri & & & 0,99 \\
\hline Meme & $0(0,0)$ & $0(0,0)$ & \\
\hline Uzak metastaz & $2(66,7)$ & $2(66,7)$ & \\
\hline Her ikisi & $1(33,3)$ & $1(33,3)$ & \\
\hline Memede hastalık & & & 0,99 \\
\hline Yeni primer & $0(0,0)$ & $0(0,0)$ & \\
\hline Gerçek nüks & $1(100,0)$ & $1(100,0)$ & \\
\hline Lokal nüks yeri & & & 0,99 \\
\hline Meme & $0(0,0)$ & $0(0,0)$ & \\
\hline Göğüs duvarı & $1(100,0)$ & $1(100,0)$ & \\
\hline $\begin{array}{l}\text { Bölgesel nüks (aksilla, } \\
\text { supraklavikuler, } \\
\text { infraklavikuler bölge) }\end{array}$ & & & 0,99 \\
\hline Var & $0(0,0)$ & $2(100,0)$ & \\
\hline Yok & $0(0,0)$ & $0(0,0)$ & \\
\hline Uzak metastaz yeri & & & 0,40 \\
\hline Karaciğer & $0(0,0)$ & $1(33,3)$ & \\
\hline Kemik & $3(100,0)$ & $1(33,3)$ & \\
\hline Multipl & $0(0,0)$ & $1(33,3)$ & \\
\hline
\end{tabular}

n (\%)

Tablo 4: Yaşam sürelerinin yaş gruplarına göre karşılaştırmaları

\begin{tabular}{lccc}
\hline & \multicolumn{2}{c}{ Yaş Grupları } & \multirow{2}{*}{ p } \\
\cline { 2 - 3 } & 35 Yaş Altı & 36-40 Yaş Arası & \\
\hline HS (median) & $21(7-38,25)$ & $14(6-33)$ & 0,250 \\
\hline GS (median) & $22,5(7,25-28,25)$ & $15(6-33)$ & 0,450 \\
\hline
\end{tabular}

GS: Genel sağkalım (ay), HS: Hastalıksız sağkalım (ay) 
Yine yapılan sağkalım analizinde çok genç meme kanseri grubu ve genç meme kanseri grubu arasında istatistiksel olarak anlamlı bir genel ve hastalıksız sağkalım farkının olmadığı görüldü ( $G S, p=0,45 ; H S, p=0,25)$.

Çalışmanın sınırlılıkları, retrospektif bir çalışma olması ve hasta sayısının az olmasıdır.

\section{SONUÇ}

Genç yaş hastalardaki meme kanseri hem hastalık özellikleri hem de sağkalım açısından diğer ileri yaş grubu meme kanseri hastalarına göre daha kötü seyretmektedir. Fakat bu grup içerisinde özellikle moleküler alt gruplandırma açısından ve sağkalım açısından 35 yaş ve altı olarak değerlendirilen çok genç meme kanseri grubunun ayrı bir grup olarak değerlendirilmesi gerekmeyebilir.

Hem moleküler sınıflandırma, hem hastalık durumu, hem de sağkalım analizi açısından 35 yaş altında tanı alan hastaların, 40 yaş altı meme kanseri grubu içinde ayrı bir grup olarak değerlendirilmesinin istatistiksel olarak anlamlı olmadığı görülmüştür. Özellikle meme kanseri tanı konulma yaşının oldukça genç yaşlara indiği günümüzde 40 yaş ve altının kötü prognozu sebebiyle daha dikkatli değerlendirilmesi ve özenli tedavisi gerekmektedir. Daha genç yaşlarda tanı alan ve çok genç meme kanseri grubuna giren kişiler için ek bir değerlendirme veya gruplandırma ayrımı ihtiyacı yoktur.

\section{Teşekkür}

\section{Bulunmuyor}

\section{Yazar Katkı Beyanı}

Fikir: Sertaç Ata Güler, Tasarım: Alican Güreşin, Denetleme: Turgay Şimşek, Kaynaklar: Turgay Şimşek, Malzemeler: Saffet Çınar, Veri Toplanması ve/veya İşlemesi: Saffet Çınar, Analiz ve/veya Yorum: Nihat Zafer Utkan Literatür Taraması: Nuh Zafer Cantürk, Yazıyı Yazan: Sertaç Ata Güler, Eleştirel İnceleme: Alican Güreşin.

\section{Çıkar Çatışması}

Yazarların beyan edecek çıkar çatışması yoktur.

Finansal Destek

Yazarlar bu çalışma için finansal destek almadıklarını beyan etmişlerdir.

\section{Etik Kurul Onayı}

$\mathrm{Bu}$ araştırma, ilgili tüm ulusal düzenlemelere, kurumsal politikalara ve Helsinki Bildirgesinin ilkelerine uygundur ve Kocaeli Üniversitesi Tıp Fakültesi Etik Kurulu tarafından onaylanmıştır (onay numarası: 2020/137).

\section{Hakemlik Süreci}

Kör hakemlik süreci yayınlanmaya uygun bulunmuş ve kabul edilmiştir.

\section{KAYNAKLAR}

1. Rosenberg SM, Partridge AH. Management of breast cancer in very young women. Breast 2015; 24(2): 154-158.

2. Azim HA Jr, Partridge $\mathrm{AH}$. Biology of breast cancer in young women. Breast Cancer Res 2014; 16(4): 427.

3. Keegan TH, DeRouen MC, Press DJ, Kurian AW, Clarke CA. Occurrence of breast cancer subtypes in adolescent and young adult women. Breast Cancer Res 2012; 27;14(2):R55.

4. Radecka B, Litwiniuk M. Breast cancer in young women. Ginekol Pol 2016; 87(9):659-663.

5. Farouk O, Ebrahim MA, Senbel A, Emarah Z, Abozeed W, Seisa MO, Mackisack S, Abdel Jalil S, Abdelhady S. Breast cancer characteristics in very young Egyptian women $\leq 35$ years. Breast Cancer (Dove Med Press. 2016; 5;8:53-58.

6. Eiriz IF, Vaz Batista M, Cruz Tomás T, Neves MT, Guerra-Pereira $\mathrm{N}$, Braga S. Breast cancer in very young women-a multicenter 10-year experience. ESMO Open 2021;6(1):100029.

7. Assi HA, Khoury KE, Dbouk H, Khalil LE, Mouhieddine TH, El Saghir NS. Epidemiology and prognosis of breast cancer in young women. J Thorac Dis 2013; 5(Suppl. 1):S2e8.

8. Cardoso F, LoibI S, Pagani O, Graziottin A, Panizza P, Martincich L, Gentilini O, Peccatori F, Fourquet A, Delaloge S, Marotti L, Penault-Llorca F, Kotti-Kitromilidou AM, Rodger A, Harbeck N; European Society of Breast Cancer Specialists. The European Society of Breast Cancer Specialists recommendations for the management of young women with breast cancer. Eur J Cancer 2012; 48(18):3355-3377.

9. Winchester DP, Osteen RT, Menck HR. The National Cancer Data Base report on breast carcinoma characteristics and outcome in relation to age. Cancer 1996; 78: 1838-1843.

10. Bartelink H, Horiot JC, Poortmans P, Struikmans H, Van den Bogaert W, Barillot I, Fourquet A, Borger J, Jager J, Hoogenraad W, Collette L, Pierart M, European Organization for Research and Treatment of Cancer Radiotherapy and Breast Cancer Groups. Recurrence rates after treatment of breast cancer with standard radiotherapy with or without additional radiation. N Engl J Med 2001;345(19):1378-1387.

11. Veronesi U, Marubini E, Mariani L, Galimberti V, Luini A, Veronesi P, Salvadori B, Zucali R. Radiotherapy after breastconserving surgery in small breast carcinoma: Long-term results of a randomized trial. Ann Oncol 2001;12(7):997-1003.

12. Collins LC, Marotti JD, Gelber S, Cole K, Ruddy K, Kereakoglow S, Brachtel EF, Schapira L, Come SE, Winer EP, Partridge AH. Pathologic features and molecular phenotype by patient age in a large cohort of young women with breast cancer. Breast Cancer Res Treat 2012;131:1061-1066. 